\title{
ARCH DEVELOPMENT FOR MODERATE CROWDING USING SELF LIGATING BRACKETS: A CASE REPORT
}

\author{
Thamer Alkhadra*
}

\begin{abstract}
The use of self ligating bracket system is gaining popularity because of its effectiveness in treating patients with moderate crowding using a non extraction therapy. The author report a case of 14 year 3 months old female who presented to the orthodontic clinic with moderate upper and lower anterior crowding, proclination of upper anterior and increased overjet and overbite. It was decided to treat the case with non extraction orthodontic therapy using self ligating bracket system. Following 28 months of treatment time, there was a favorable outcome in the profile of the patient. The patient presented with Class I molar and canines relationships bilaterally with normal overjet and overbite after the conclusion of the treatment. The present case study demonstrates that self ligating bracket system could be feasible choice in treating moderate to severe crowding cases without extraction therapy.
\end{abstract}

KEYWORDS: Crowding, Self-Ligating Brackets, Damon Brackets, Non extraction

\section{INTRODUCTION}

The advent of Damon system by Dwight Damon in 1990's is gaining importance at a rapid pace among the orthodontist worldwide. ${ }^{1}$ This is due to the fact that Damon bracket system have revived the non extraction orthodontic therapy in resolving minor to moderate crowding cases. ${ }^{2}$ The Damon system incorporates low force and low friction wire technology with the use of passive self-ligating brackets. ${ }^{3}$ They have several advantages over the traditional or ligated bracket system such as saving time during appointments, enhanced efficacy of treatment, increased patient comfort and excellent final treatment results. ${ }^{4}$

Furthermore, thefriendly light forces in Damon system do not affect the oral musculature. The expansion in the damon system occurs at the posterior region which is the path of least resistance. ${ }^{5,6}$ The anterior movements of incisors are restricted by perioral muscles, the orbicularis oris and the mentalis muscle. Damon further stated that with his system, there is no significant change in the mandibular intercanine width and very minimal labial movement of incisors do occur. ${ }^{5}$

* Associate Professor, Department of Pediatric Dentistry and Orthodontics, College of Dentistry, King Saud University 


\section{CASE PRESENTATION}

A 14 years 3 month old Saudi patient presented to Orthodontic clinic with a chief complaint of crooked upper and lower teeth. The patient had no history of any significant medical and dental history. On examination, she had mesocephalic face with equal facial proportion. The profile was straight with inconsonant smile and lips were competent with slightly retrusive upper lip (Figure 1). On intra oral examination, the patient had class 1 molar relation bilaterally. The overjet was $4 \mathrm{~mm}$ and overbite was $60 \%$. The anterior crowding was $6 \mathrm{~mm}$ in upper arch and $7 \mathrm{~mm}$ in lower arch. The patient had a slight buccal corridor. Upper dental midline was shifted to the left for $1 \mathrm{~mm}$ relative to the facial midline (Figure 2). The radiographic examination revealed normal morphology of the condylar head and neck, no bony pathologies and normal maxillary sinus borders. The cephalometric radiograph presented with slight skeletal class I relationship with equal facial proportion. Upper teeth were slightly proclined and lower teeth were normally positioned. The soft tissue analysis presented with obtuse naso - labial angle with retrusive upper lip (Figure 3).

After complete intra oral and extra oral examination and radiographic analysis, the patient was diagnosed with Angle's class I malocclusion with moderate upper and lower anterior crowding and proclination of upper anterior and increased overjet and overbite.

The treatment objective was to improve the lips position, harmony and smile esthetics in soft tissues. Dentally the objective was to relieve upper and lower crowding, achieve normal overbite and overjet and to correct upper midline deviation.

After considering all the aspects, it was planned for Comprehensive, non-surgical, non-extraction orthodontic treatment. Damon ${ }^{\circledR}$ self ligating bracket (Ormco Corporation, Orange, California, USA) system was used for treatment as there was scope for expansion in both lower and upper posterior region. The self-ligating brackets can be a good treatment option for cases with moderate to severe arch crowding where extraction is not indicated because of an acceptable or obtuse profile as seen in the present case which helps to develop the arch posteriorly.

The upper and lower 6's were bonded and Damon prescription bracket (0.022-in, Straight Wire) was bonded from premolar to premolar. The treatment stages included a) Leveling and alignment, b) Interproximal reduction and c) finishing and detailing. The retention plan was upper wrap around Hawley retainer and a lower canine to canine fixed retainer.

The initial leveling and aligning was carried out using 0.014 X 0.025" Damon Copper NiTi. After the initial arch wire a 017 X 0.025 " copper NiTi was placed for the sequential leveling. A TMA wire of 017 X 0.025 " in upper and lower arch was placed to start finishing and detailing process. Box elastic with class II component $(4.5 \mathrm{oz}, 1 / 4)$ was placed for midline correction. After discontinuing box elastic, power chain was placed from molar to molar in both arches. The total treatment duration was 28 months.

The post treatment extra oral photographs showed a favorable outcome in the profile of the patient (Figure 4). The post treatment intra oral photographs showed a Class I molars relationships bilaterally with normal overjet and overbite. The upper and lower midline was in straight line (Figure 5). Following the conclusion of the treatment procedure, upper wrap around retainer and lower canine to canine fixed retained were placed.

The cranial base superimposition showed forward and downward movement of nose tip by $1 \mathrm{~mm}$, forward and upward movement of upper lip by $0.5 \mathrm{~mm}$, forward and downward movement of lower lip by $0.5 \mathrm{~mm}$, forward movement of soft tissue pogonion (Pog') by $1 \mathrm{~mm}$ and downward and forward movement of mandible (Figure 6).

The comparison of pre and post treatment cephalometric readings demonstrated overall growth of face and forward movement of upper and lower incisors (Table 1). 


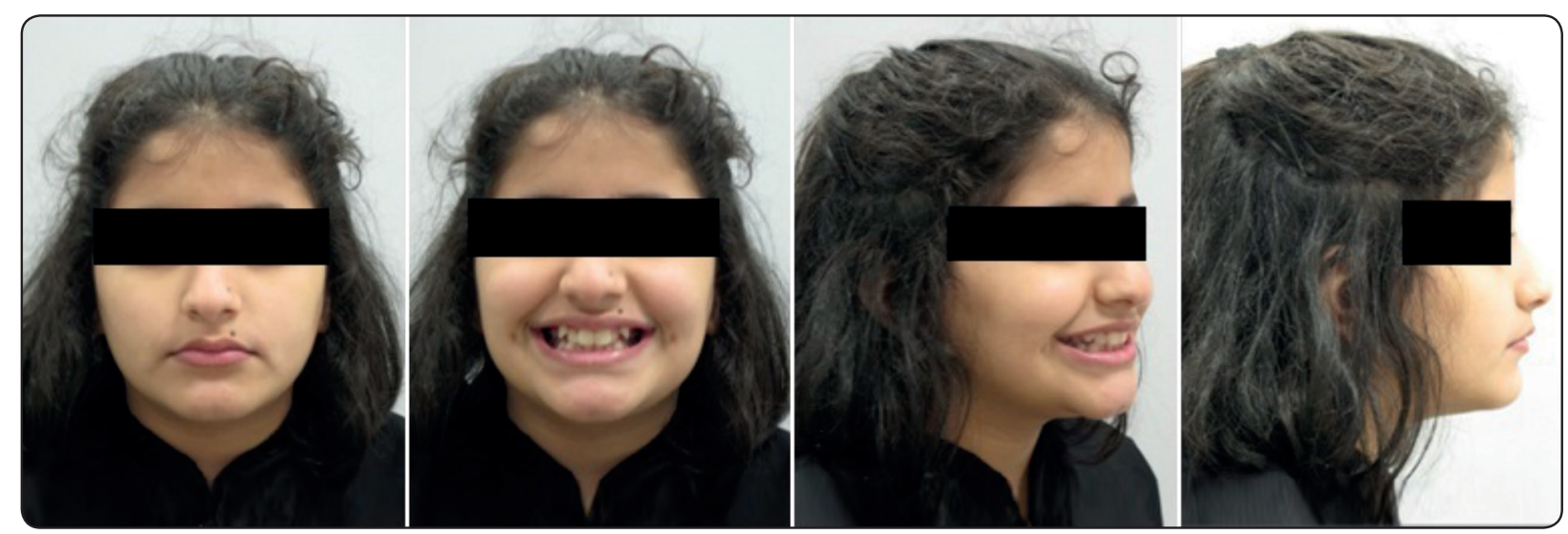

Fig. (1) Pre treatment extra oral photographs
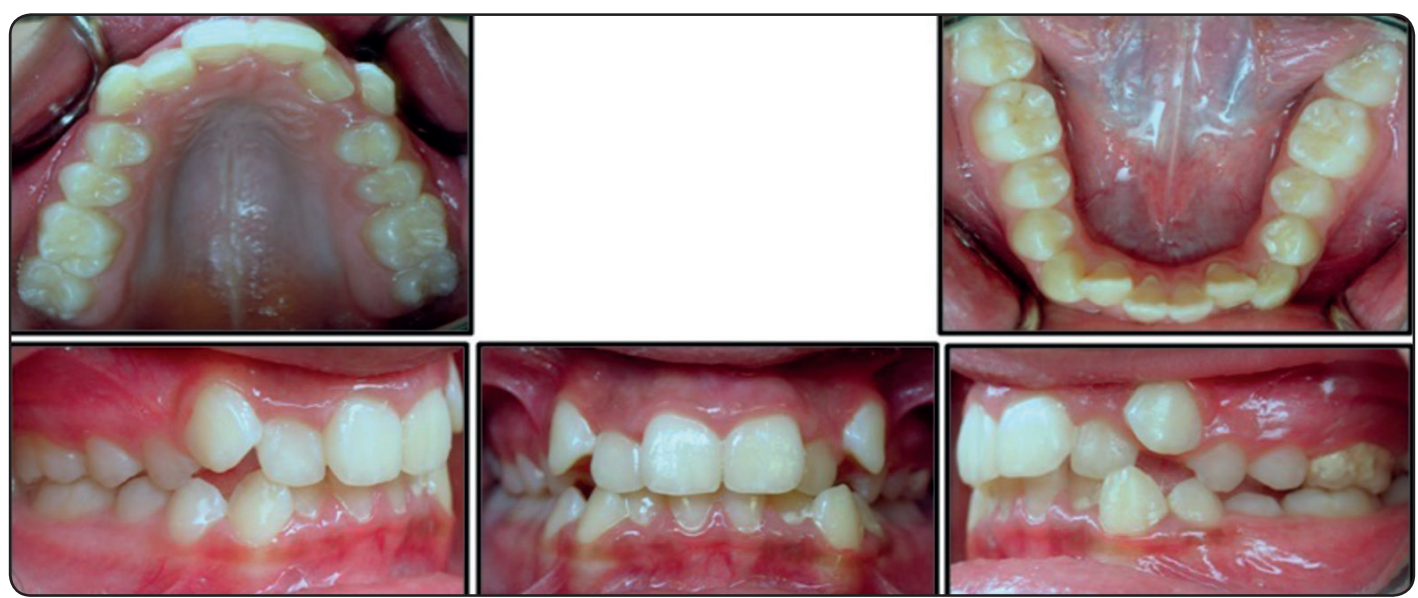

Fig. (2) Pre treatment intra oral photographs
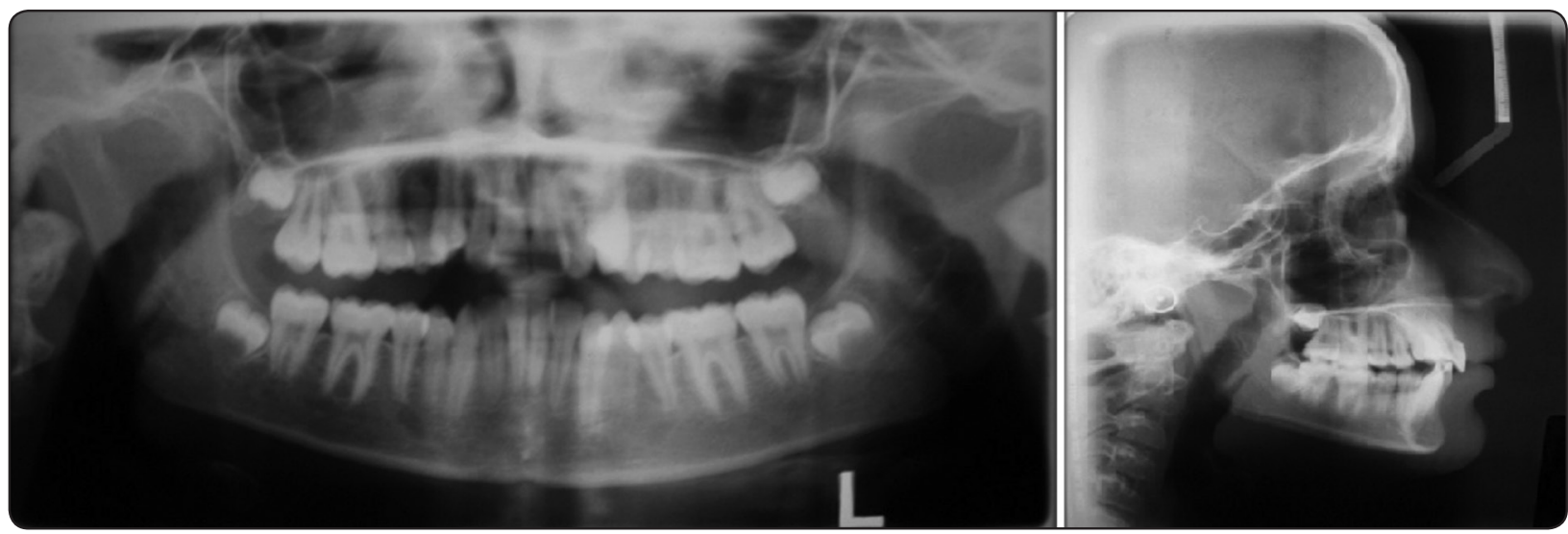

Fig. (3) Pre treatment radiographs A) orthopantomograph B) Lateral Cephalogram 


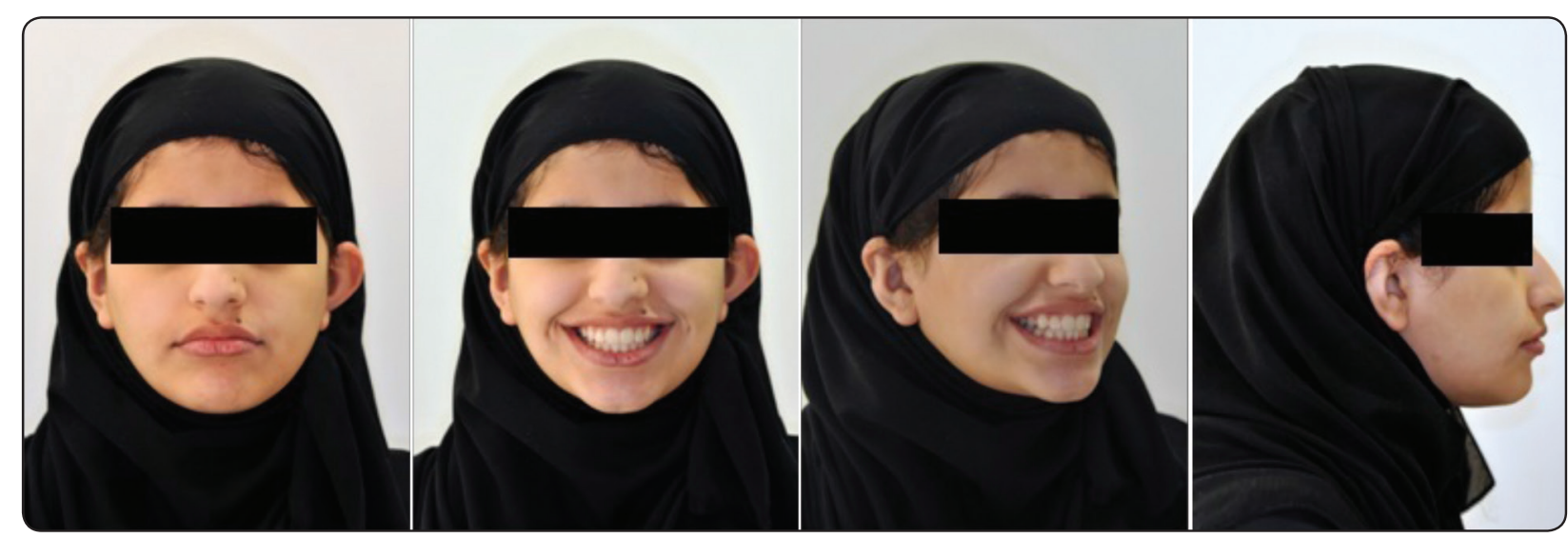

Fig. (4) Post treatment extra oral photographs

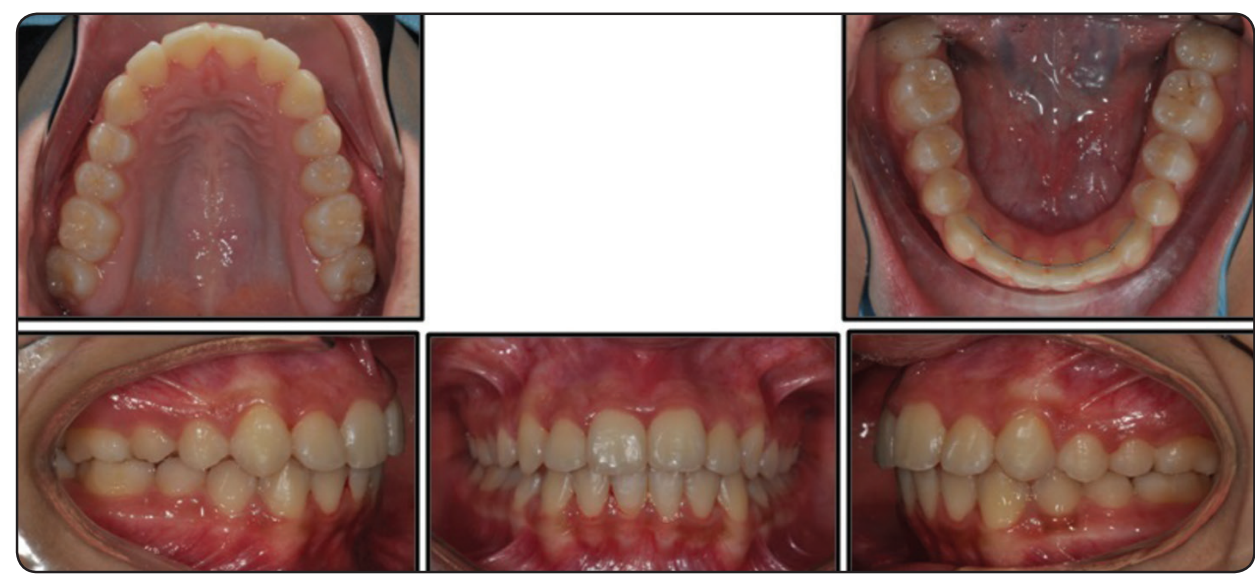

Fig. (5) Post treatment intra oral photographs

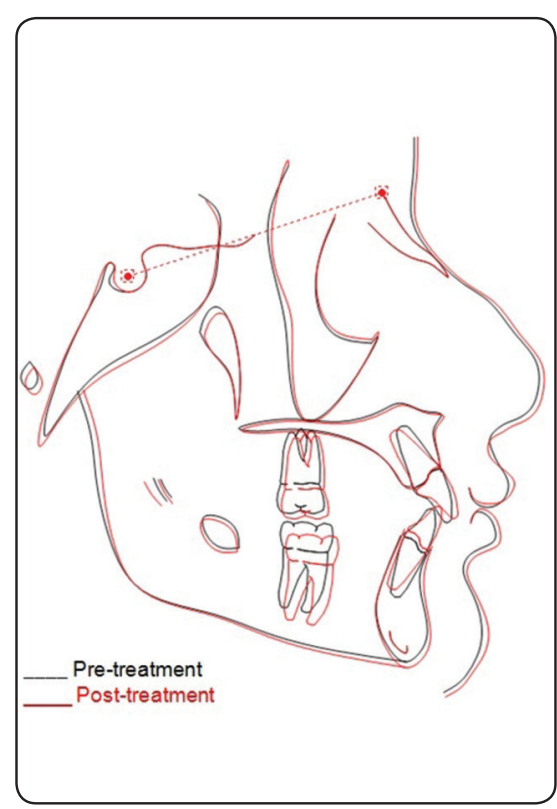

Fig. (6) Cranial base superimposition 
TABLE (1) Comparison of pre and post treatment cephalometric measurements

\begin{tabular}{|c|c|c|c|}
\hline Measurements & $\begin{array}{l}\text { Normal } \\
\text { values }\end{array}$ & Pre-treatment values & $\begin{array}{c}\text { Post-treatment } \\
\text { values }\end{array}$ \\
\hline \multicolumn{4}{|l|}{ Sagittal Relationship } \\
\hline SNA & $82 \circ \pm 2 \circ$ & $82 \circ$ & $82 \circ$ \\
\hline SNB & $80^{\circ} \pm 2^{\circ}$ & $78^{\circ}$ & $79^{\circ}$ \\
\hline ANB & $2^{\circ} \pm 2^{\circ}$ & $4^{\circ}$ & $3^{\circ}$ \\
\hline Wits Appraisal & -1 to $0 \mathrm{~mm}$ & $4 \mathrm{~mm}$ & $5 \mathrm{~mm}$ \\
\hline SN-Pog & $80^{\circ} \pm 3^{\circ}$ & $79 \circ$ & $79.5^{\circ}$ \\
\hline NA-A Pog & $0^{\circ} \pm 5.1^{\circ}$ & $8^{\circ}$ & $11^{\circ}$ \\
\hline NSBa & $130^{\circ} \pm 6^{\circ}$ & $134 \circ$ & $135^{\circ}$ \\
\hline \multicolumn{4}{|l|}{ Vertical Relationship (Divergence) } \\
\hline SN to Palatal Pl. & $8^{\circ} \pm 3 \circ$ & $9 \circ$ & $13^{\circ}$ \\
\hline SN to Mand. Pl. & $32^{\circ} \pm 5.1^{\circ}$ & $29 \circ$ & $34 \circ$ \\
\hline Palatal Pl. to Mand. Pl. & $25^{\circ} \pm 3 \circ$ & $22^{\circ}$ & $27 \circ$ \\
\hline Y-Axis (N-S-Gn) & $59.4 \circ \pm 3.8^{\circ}$ & $60^{\circ}$ & $65^{\circ}$ \\
\hline Face Height (ANS-Me/N-Me) & $55 \% \pm 3 \%$ & $51 \%$ & $56 \%$ \\
\hline \multicolumn{4}{|l|}{ Dental Relationship } \\
\hline U Inc. to L Inc. & $131 \circ \pm 5^{\circ}$ & $130^{\circ}$ & $120^{\circ}$ \\
\hline U Inc. to SN & $104 \circ \pm 2 \circ$ & $106^{\circ}$ & $109 \circ$ \\
\hline U Inc. to Palatal Pl. & $110^{\circ} \pm 6^{\circ}$ & $108^{\circ}$ & $118^{\circ}$ \\
\hline U Inc. to NA & $22 \circ / 4 \mathrm{~mm}$ & $22 \circ / 4 \mathrm{~mm}$ & $26 \circ / 6 \mathrm{~mm}$ \\
\hline L Inc. to NB & $25 \circ / 4 \mathrm{~mm}$ & $25 \circ / 4 \mathrm{~mm}$ & $32 \circ / 8 \mathrm{~mm}$ \\
\hline L Inc. to A Pog & $1 \pm 2 \mathrm{~mm}$ & $3 \mathrm{~mm}$ & $6 \mathrm{~mm}$ \\
\hline L Inc. to Mand. Pl. & $93 \circ \pm 6^{\circ}$ & $96 \circ$ & $108^{\circ}$ \\
\hline \multicolumn{4}{|l|}{ Soft Tissue Relationship } \\
\hline U Lip to E-line & $-4 \pm 2 \mathrm{~mm}$ & $-4.5 \mathrm{~mm}$ & $-4 \mathrm{~mm}$ \\
\hline L Lip to E-line & $-2 \pm 2 \mathrm{~mm}$ & $3.5 \mathrm{~mm}$ & $-1 \mathrm{~mm}$ \\
\hline Nasio-Labial Angle & $90 \circ-110^{\circ}$ & $105^{\circ}$ & $98 .^{\circ}$ \\
\hline
\end{tabular}

\section{DISCUSSION}

The introduction of self ligating bracket dates back to 1930's when Stolzenberg introduced the Russell attachment. ${ }^{7}$ The Russell attachment was more pleasant to the patient and had a reduced visit time. The lack of promotion or less popularity at that time resulted in disappearing of the Russell attachment from the market ${ }^{8}$. The interest in self ligating bracket has been revived in past decades with the introduction of new bracket systems into the market. These bracket systems are reported to have many advantages over the conventional edgewise bracket system. ${ }^{5,9,10}$ 
The self-ligating brackets are of two types based on their mechanisms of closure; active and passive. The active types of brackets have a spring clip that stores energy and presses against the archwire and provides active seating force on the archwire thus ensuring engagement for rotation and torque control. The examples of active type of brackets are In-Ovation, SPEED and Time. In the passive selfligating brackets, the clip does not press against the archwire but these brackets use a rigid door to hold the archwire providing more room for the archwire. Damon and SmartClip are the popular brands of passive type. ${ }^{8}$ The most renowned self-ligating bracket system is the Damon system introduced by Dr. Dwight Damon in 1996. ${ }^{11}$

The advantages of the self-ligating bracket are reported after comparing the performance with the conventional edgewise brackets. The reduced friction with self-ligating brackets is the primary advantage over conventional brackets system. The reduced friction requires less force to bring the tooth movement. ${ }^{3,12}$ The self-ligating brackets are reported to produce more physiologically harmonious tooth movement without much effect on the musculature and interruption with the periodontal vascular supply. ${ }^{10}$ So this result in more alveolar bone generation, increased expansion, less proclination of anterior teeth and less need for extractions. Other advantages include reduced friction between archwire and bracket, reduced orthodontic forces, better alignment and occlusal outcomes, decreased treatment time, faster alignment, faster space closure, different arch dimensions, less patient discomfort and improved oral hygiene.

The self-ligating brackets do possess some disadvantages such as high cost, possible breakage of the slide or the clip, complicated mechanical design, more occlusal interferences and lip discomfort and difficulty in finishing due to incomplete expression of the archwires. ${ }^{8}$

The main objective of the present case report was to demonstrate a more efficient method of managing moderate crowding cases. This is important because such cases are usually treated by extraction of upper and lower first premolars by pre-adjusted edgewise appliance. The present case used self ligating Damon brackets with non extraction approach for treating moderate crowding.

Previous studies have reported that in non extraction therapeutic approach to treat crowding cases, expansion of the buccal segments together and advancement of the mandibular incisors is necessary. ${ }^{2,6,13}$ The Damon self ligating bracket produces passive expansion effect by copper NiTiwires used throughout the treatment. Additionally mandibular intermolar width would also increase significantly compared to the conventional bracket system. ${ }^{5}$

\section{CONCLUSION}

The present case study demonstrated that Damon self ligating bracket system could be feasible choice in treating moderate to severe crowding cases without extraction therapy.

\section{REFERENCES}

1. Vajaria R, BeGole E, Kusnoto B, et al. Evaluation of incisor position and dental transverse dimensional changes using the Damon system. Angle Orthod 2011;81:647-652.

2. Weinberg M, Sadowsky C. Resolution of mandibular arch crowding in growing patients with Class I malocclusions treated nonextraction. Am J Orthod Dentofacial Orthop 1996;110:359-364.

3. Kim T-K, Kim K-D, Baek S-H. Comparison of frictional forces during the initial leveling stage in various combinations of self-ligating brackets and archwires with a custom-designed typodont system. Am J Orthod Dentofacial Orthop 2008;133:187.e115-187.e124.

4. Revanappa S, Doshi J. Correction of Severely Crowded Lower Anterior Teeth Using Self-Ligating Bracket System- A Case Report. Iran J Ortho 2017; In Press:e9472.

5. Damon DH. The Damon low-friction bracket: a biologically compatible straight-wire system. J Clin Orthod 1998;32:670-680. 
6. Pandis N, Polychronopoulou A, Eliades T. Self-ligating vs conventional brackets in the treatment of mandibular crowding: a prospective clinical trial of treatment duration and dental effects. Am J Orthod Dentofacial Orthop 2007;132:208-215.

7. Stolzenberg J. The Russell attachment and its improved advantages. International Journal of Orthodontia and Dentistry for Children 1935;21:837-840.

8. Chen SS, Greenlee GM, Kim JE, et al. Systematic review of self-ligating brackets. Am J Orthod Dentofacial Orthop 2010;137discussion 726-727.

9. Berger JL. The SPEED System: An Overview of the Appliance and Clinical Performance. Sem Ortho 2008; 14:54-63.
10. Damon DH. The rationale, evolution and clinical application of the self-ligating bracket. Clin Orthod Res 1998;1:52-61.

11. Zreaqat M, Hassan R. Self-Ligating Brackets: An Overview In: Naretto S, ed. Principles in Contemporary Orthodontics: InTech, 2011;30.

12. Berger JL. The influence of the SPEED bracket's self-ligating design on force levels in tooth movement: a comparative in vitro study. Am J Orthod Dentofacial Orthop 1990;97:219-228.

13. Fleming PS, DiBiase AT, Sarri G, et al. Comparison of mandibular arch changes during alignment and leveling with 2 preadjusted edgewise appliances. Am J Orthod Dentofacial Orthop 2009;136:340-347. 